\title{
Acromion tumour as the primary presentation of multiple myeloma: case report
}

\author{
Anupam Mahajan $^{1 *}$, Bobby John ${ }^{2}$, M Joseph John ${ }^{3}$ \\ ${ }^{1}$ Associate Professor, Department of Orthopaedics, Christian Medical College and Hospital, Ludhiana, Punjab, India -141008 \\ ${ }^{2}$ Professor, Department of Orthopaedics, Christian Medical College and Hospital, Ludhiana \\ ${ }^{3}$ Associate Professor, Department of Haemato-Oncology, Christian Medical College and Hospital, Ludhiana \\ *Corresponding author E-mail: dranupammahajan@yahoo.com
}

Copyright () 2014 Anupam Mahajan et al. This is an open access article distributed under the Creative Commons Attribution License, which permits unrestricted use, distribution, and reproduction in any medium, provided the original work is properly cited.

\begin{abstract}
A 52-year-old male presented with complaints of progressively increasing pain in the tip of right shoulder for 4 months and swelling for 3 months. Radiographs revealed an expansile osteolytic lesion involving the acromion process of scapula. Biopsy was suggestive of multiple myeloma/plasmacytoma. Diagnosis of Multiple Myeloma was confirmed on histopathology, bone marrow examination and $\mathrm{M}$ band on serum protein electrophoresis. To the best of our knowledge there is no published record of an acromion tumour as the primary presentation of multiple myeloma.
\end{abstract}

Keywords: Acromion, Multiple Myeloma, Primary Presentation, Scapula, Tumor.

\section{Introduction}

Multiple myeloma is a subgroup of plasma cell dyscrasias in which there is a neoplastic proliferation of plasma cells or their precursors. It usually affects flat bones of the skeletal system - sternum, vertebra and pelvis being the usual sites. It rarely involves the scapula primarily. As per our knowledge there is no published record of an acromion tumour as the primary presentation of multiple myeloma.

\section{Case report}

A 52-year-old male presented with complaints of progressively increasing pain in the tip of right shoulder for 4 months. Initially, he was diagnosed to have supraspinatus tendinitis and treated for the same elsewhere. One month later to onset of pain, he noticed a progressively increasing swelling over the tip of right shoulder. There was no history of fever, loss of weight or appetite. On examination, there was an ill-defined approximately $3 \mathrm{~cm} \times 3 \mathrm{~cm}$ tender swelling over the acromion process and it was fixed to the underlying bone. Temperature over the swelling was normal. There were no sinuses, scars or dilated veins. Movements at the shoulder joint were restricted due to pain. A radiograph done (fig 1) showed an expansile osteolytic lesion of the acromion process of the right scapula. 


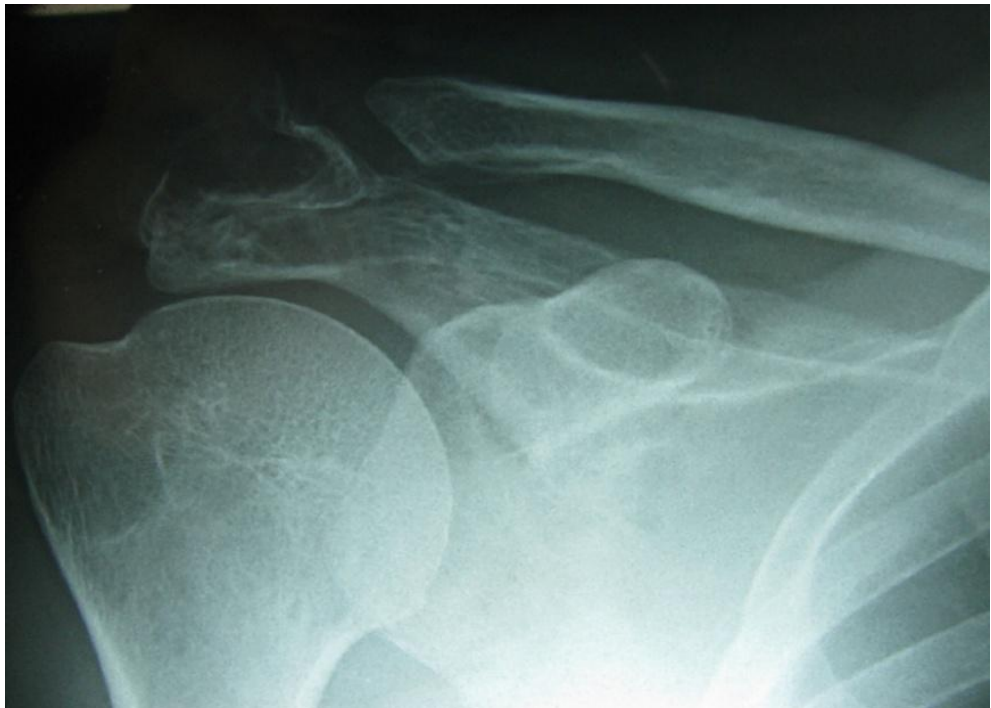

Fig. 1: Radiograph of Right Shoulder Showing Expansile Osteolytic Lesion Involving the Acromion Process of Scapula

Magnetic resonance imaging (fig 2) revealed an expansile lobulated lesion of the right acromion with cortical breech superiorly without any muscular involvement.

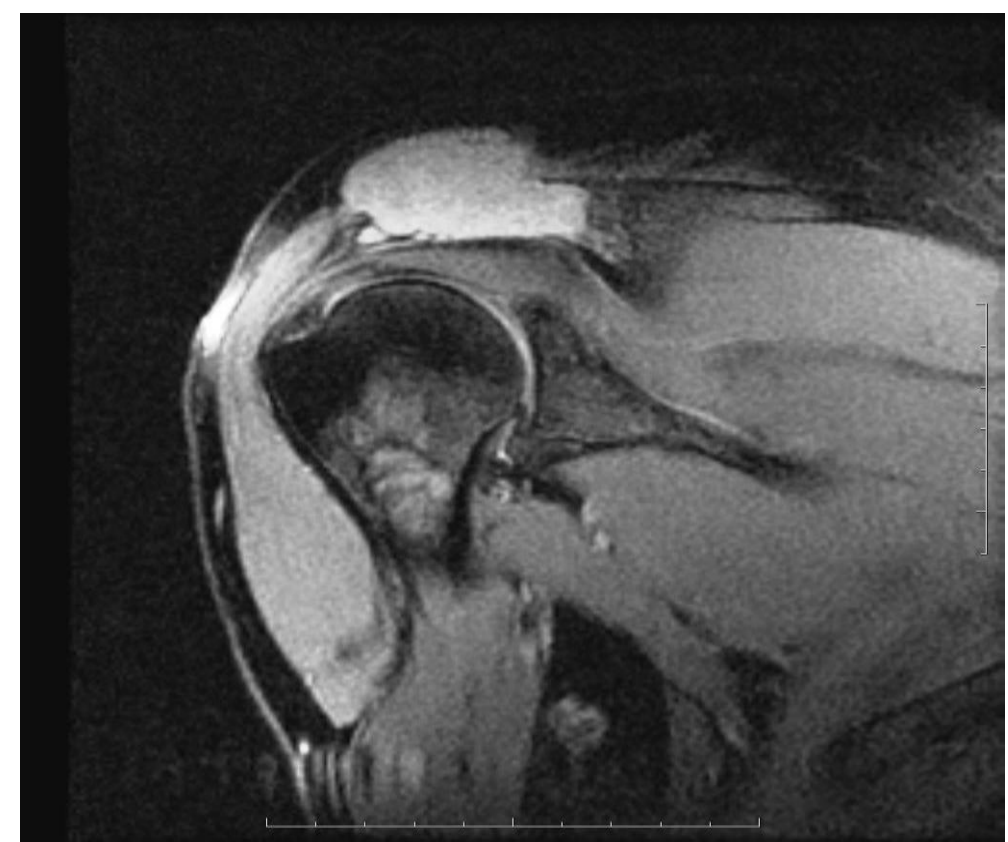

Fig. 2: T2 Fat Suppressed MRI of the Right Shoulder Revealing an Expansile Lobulated Lesion of the Right Acromion with Cortical Breech Superiorly without Any Muscular Involvement

The differential diagnoses of aneurysmal bone cyst, giant cell tumour or secondaries were kept in mind.

Haematological profile showed hemoglobin of $10.4 \mathrm{~g} / \mathrm{dl}$ (Normal: $14-16 \mathrm{~g} / \mathrm{dl}$ ). Differential count and coagulation profiles were normal. Serum calcium was $9.2 \mathrm{mg} / \mathrm{dL}$. Alkaline phosphatase was normal. There was a reversal of the albumin globulin ratio to $1: 1.37$. Serum creatinine was $1.1 \mathrm{mg} / \mathrm{dL}$. There were no Bence Jones proteins in the urine. Serum protein electrophoresis showed presence of an M band (2.91 gm \%). Beta 2 microglobulin levels were $6.8 \mathrm{mg} / \mathrm{dL}$. Immunoglobulin levels were as follows: $\mathrm{IgG}-2850 \mathrm{gm} / \mathrm{dL}, \mathrm{IgA}-175 \mathrm{gm} / \mathrm{dL}, \mathrm{IgM}-30 \mathrm{gm} / \mathrm{dL}$.

A skeletal survey was done which did not reveal any other lesion. Intra-operative frozen section of a curettage and biopsy revealed sheets of closely placed mature and immature plasma cells suggestive of plasmacytoma/ multiple myeloma. A bone marrow aspiration revealed $9 \%$ plasma cells.

A diagnosis of Multiple Myeloma stage III according to International Staging System was made on the basis of presence of $\mathrm{M}$ band, histopathology showing plasmacytoma and related organ tissue impairment (ROTI) with anaemia and raised beta 2 microglobulin[1]. The patient was started on chemotherapy in consultation with the clinical haematooncologist (Thalidomide/Dexamethasone protocol). The patient responded to treatment with remission of shoulder pain and regaining movements within three weeks of starting treatment. 


\section{Discussion}

Multiple myeloma is a disease of neoplastic plasma cells that synthesize abnormal amounts of immunoglobulin or immunoglobulin fragments. Clinical manifestations are heterogeneous but include formation of tumour, monoclonal immunoglobulin production, and decreased immunoglobulin secretion of normal plasma cells leading to hypoglobulinemia, impaired hematopoiesis, osteolytic bone disease, hyperkalemia, and renal dysfunction [2].

The occurrence of myeloma lesion in scapula is rare. One of the largest series on scapular tumours reported 21 cases of myeloma (out of 224 scapular tumours) [3]. In another series only two cases of solitary plasmacytoma were reported out of 271 scapular tumours [4]. Besides this, only sporadic cases of myeloma in scapula have been reported. To our knowledge, there is no reported case of acromion tumour being the primary presentation of multiple myeloma.

The knowledge that some bone locations have a predilection for certain neoplasms is useful in arriving at the correct diagnosis and treatment. Scapula is a small bone with a high proportion of malignant tumours. The Musculoskeletal Tumour Society has developed a classification system that divides the scapula in two zones: S1 - the blade/spine complex and S2 - the acromion/glenoid complex (Fig 3) [5].

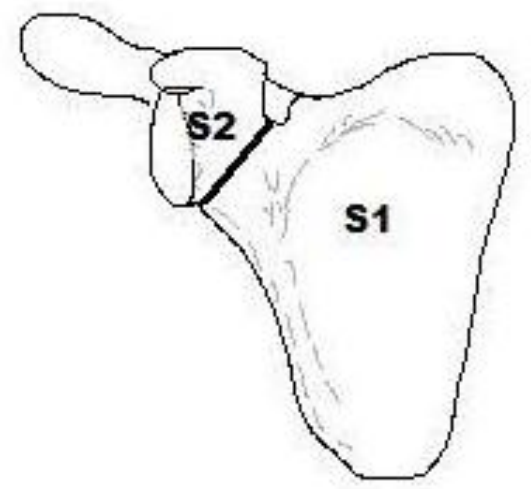

Fig. 3: Musculoskeletal Tumour Society Classification of Resection of Tumors of Shoulder Girdle Divides Scapula into Two Zones S1 (Body and Spine) and S2 (Acromion - Glenoid Complex).

The system helps to provide a functional classification for resections and reconstructions and a logical division of abnormalities that develop in the scapula. Neoplasms of S1 region are those that commonly occur in flat bones (i.e. Ewing's sarcoma, Multiple myeloma and Lymphoma). Neoplams of the S2 region commonly include tumours that develop at the end of long bones like giant cell tumour and aneurysmal bone cyst [6]. In our case, the neoplasm occurred in the S2 region and was expansile, lytic lesion mimicking an aneurysmal bone cyst or a giant cell tumour.

Treatment wise, in malignant tumours of the S2 region a part of the glenoid must be removed, which hampers the function of the shoulder. A radical acromionectomy has been reported to have poor functional outcome [7]. In myeloma/plasmacytoma, chemotherapy and radiation usually suffice along with conservative surgery. The shoulder function in this case was thus preserved.

Solitary plasmacytomas should be distinguished from multiple myeloma as the treatment and prognosis differ with systemic involvement. Solitary plasmacytomas have better prognosis and local radiotherapy usually remits or delays the progression. Systemic involvement on the other hand requires chemotherapy followed by autologous stem cell transplant [8]. In our case, the diagnosis could only be achieved after a further systemic work-up.

\section{Conclusion}

We report a rare case of multiple myeloma presenting primarily as acromion tumor. There were no other presenting signs and symptoms in this patient. The shoulder function was fully preserved after treatment.

\section{References}

[1] Greipp PR, San Miguel J, Durie BG, Crowley JJ, Barlogie B, Bladé J et al. International Staging System for Multiple Myeloma. J Clin Oncol 23 (2005) 3412-3420.

[2] Beutler E, Lichtman MA, Coller BS, Kipps TJ, Seligsohn U. Williams Hematology. $6^{\text {th }}$ ed, McGraw-Hill, New York, 2001, $1279-1305$.

[3] Ogose A, Sim FH, O'Connor MI, Unni KK. Bone tumours of the coracoid process of the scapula. Clin Orthop Relat Res 358 (1999) $205-214$.

[4] Samilson RL, Morris JM, Thompson RW. Tumours of the scapula. A review of the literature and an analysis of 31 cases. Clin Orthop Relat Res 58 (1968) 105-115.

[5] O'Connor MI, Sim FH, Chao EY. Limb salvage for neoplasms of the shoulder girdle. Intermediate reconstructive and functional results. $J$ Bone Joint Surg Am 78(12) (1996) 1872-1888.

[6] Blacksin MF, Benevenia J. Neoplasms of the scapula. Am J Roentgenol 174(6) (2000) 1729-1735.

[7] Neer CS 2nd, Marberry TA. On the disadvantages of radical acromionectomy. J Bone Joint Surg Am. 63(3) (1981) 416-419.

[8] Dimopoulos MA, Moulopoulos LA, Maniatis A and Alexanian R. Solitary plasmacytoma of bone and asymptomatic multiple myeloma. Blood 96 (2000) 2037-2044. 